Technical note

\title{
A new way of evaluating the biomechanics of the mandible with freedom in three axes in space: Technical note
}

\author{
Josete Barbosa C. Meira ${ }^{\mathrm{a}}$, Higor Landgraf ${ }^{\mathrm{b}}$, Elio Hitoshi Shinohara ${ }^{\mathrm{c}}$, João Gualberto C. Luz ${ }^{\mathrm{b}, *}$, \\ Rafael Yague Ballester ${ }^{\mathrm{a}}$
}

a Department of Biomaterials and Oral Biology, School of Dentistry, University of São Paulo, São Paulo, SP, Brazil
b Department of Oral and Maxillofacial Surgery, School of Dentistry, University of São Paulo, São Paulo, SP, Brazil

" Graduate Program, Araçatuba Dental School, Universidade Estadual Paulista "Julio de Mesquita Filho", SP, Brazil

\section{A R T I C L E I N F O}

\section{Keywords:}

Mandible

In vitro techniques

Apparatus and instruments

Elasticity

\begin{abstract}
A B S T R A C T
Objective: A biomechanical analysis of fixation devices to repair fractures or osteotomies of the mandible is carried out in hemi-mandibles fixed in the condylar process, the force is applied in the molar region and a single movement is allowed. This technical note presents a new setup for evaluating the biomechanics of the mandible with the following improvements: (1) providing freedom of mobility in three axes in the space; (2) applying forces in a way that closely replicates that of real cases; (3) capable of evaluating the fracture resistance and the stiffness and elastic recovery.

Method: A rigid metal support mounted on bearings was developed that allowed the movement and deformation of the mandible during load application to mimic its freedom of movement when in function. Steadying was only in the mandibular fossae and free in all other regions. Ten fresh sheep mandibles were subjected to testing of their rigidity and capacity for elastic recovery after a displacement of $0.75 \mathrm{~mm}$.

Results: After three displacement cycles, the mean value of stiffness was $506 \pm 64 \mathrm{~N} / \mathrm{mm}$, and the mandibles showed visco-elastic recovery.

Conclusion: This new apparatus and approach is promising for use in the evaluation of mandibular fixations.
\end{abstract}

\section{Introduction}

Laboratory studies for the biomechanical evaluation of fixation devices to repair fractures or following sagittal split osteotomy have greatly contributed to improvement of mandibular fixations. Thus, several means of fixation have been developed in terms of the types and number of plates [1,2] and the isolated use of screws [3-6]. Many studies are still researching ideal fixation methods.

The occurrence of mandibular flexure has been established and may be of clinical importance [7]. However, most studies have used models with a cantilever setup, in which one end of the specimen is held rigidly fixed and the load is applied at the other end. Comparative studies on these mechanical fixing methods have been carried out and characterized in hemi-mandibles that are fixed in the condylar process. Force is applied in the molar region until fracture [8-10]. Therefore, a single movement is allowed, and the effects are limited.

The purpose of this technical note is to present a new way of evaluating the biomechanics of the mandibles that provides freedom of movement in three axes in space and measures stiffness.

\section{Methods}

\subsection{Preparing the sheep mandibles}

Ten fresh mandibles were selected for this study from similar sheep with similar weight and ages and collected from the same abattoir. The mandibles were dissected with complete removal of soft tissues. The coronoid processes were removed to facilitate the positioning of the mandible. These were selected from a group of twenty by measuring the following distances using callipers: posterior border - mental foramen and lower border - head of the condyle. For storage, the mandibles were packed in polyethylene bags and kept in refrigeration at $20^{\circ} \mathrm{C}$ for up to $5 \mathrm{~h}$ prior to the experiment.

Because sheep mandibles have fibrous articulation in the middle region of the symphysis, they received fixation with two screws in the anterior portion to the mental foramen. This fixation was executed according to the pattern of lag screw to maintain a rigid assembly of the two hemi-mandibles. Subsequently, acrylic resin was adapted over a sectioned tube of half-round (rigid polyvinyl chloride - PVC). This PVC

\footnotetext{
* Corresponding author at: Department of Oral and Maxillofacial Surgery, School of Dentistry, University of São Paulo, Av. Prof. Lineu Prestes, 2227, 05508-900, São Paulo, SP, Brazil.

E-mail address: jgcluz@usp.br (J.G.C. Luz).
} 

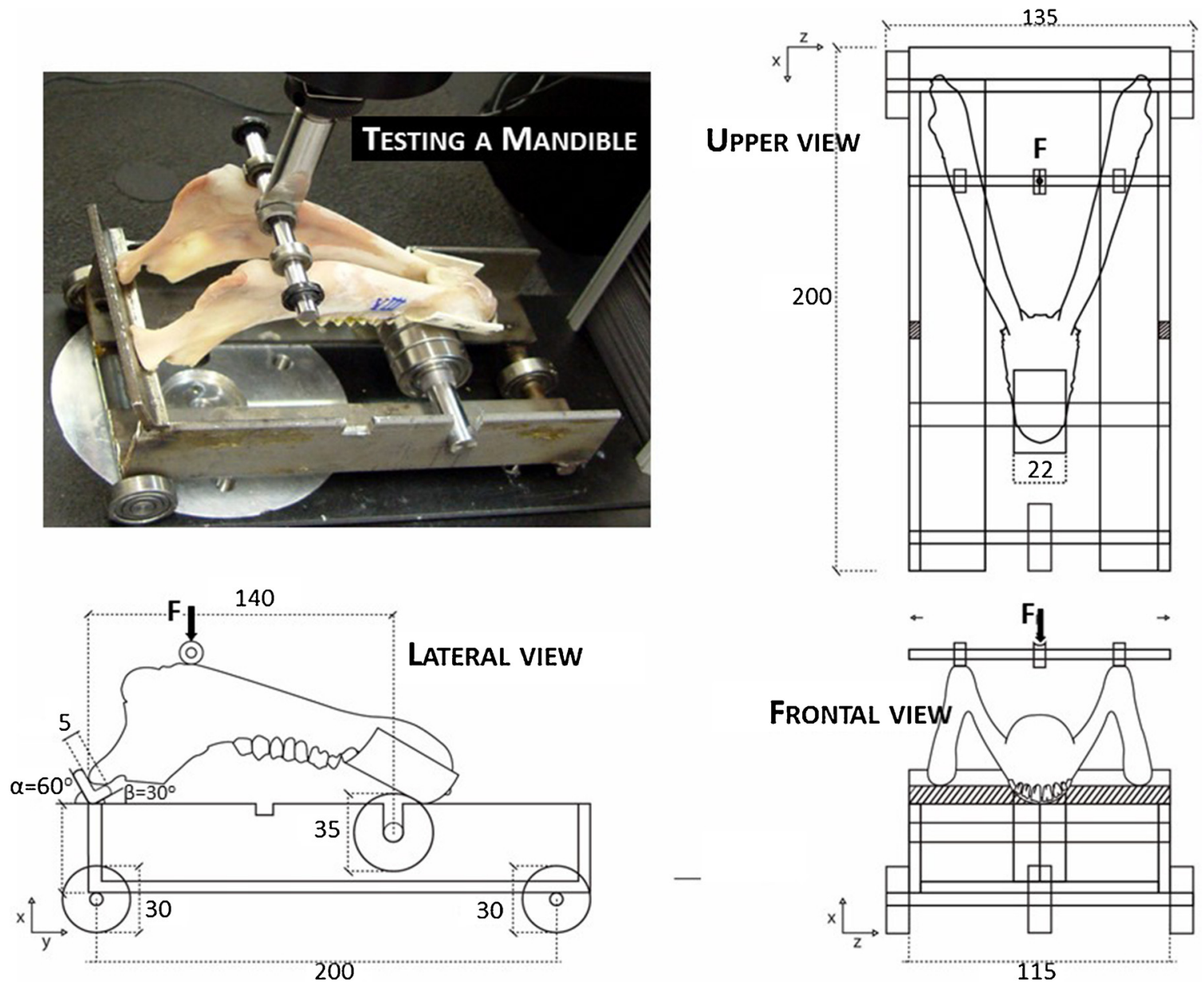

Fig. 1. Picture and the corresponding schematic drawing of a mandible assembled in the apparatus for testing.

base served as a sliding holder in each assay (Fig. 1) for the anterior region of the mandible. After correct positioning of the mandible and centralization of the apparatus on the universal testing machine, the mechanical testing was executed.

\subsection{New device support}

A rigid metal support mounted on bearings was developed to allow the movement of the whole mandible, while preserving the alignment of the load application point with the cross head of the testing machine throughout the test (Fig. 1). The load was applied on the central sliding bearing, which was mounted in a rigid metal bar with three sliding bearings. The two lateral sliding bearings were supported, stabilized and glued (acrylic resin, not represented in Fig. 1) in the left and right angles of the mandible, thus allowing the deformation of the mandible during load application by moving away or nearing the angles. The anterior region of the sheep mandibles was embedded in a PVC pipe cut into a half-round. This region was then supported over a rolling bearing to allow the deformation of the mandibles by increasing the angle between the body and the ramus to mimic the freedom of movement of a human mandible when in function. Both condyles were supported in a holder that mimicked the condylar fossa, which allowed only spinning. The mandible was free in all other regions. The positioning of the mandible in the apparatus occurred at three points of support: the condyles and the anterior region. The load application occurred bilaterally in the region between the mandibular body and angle, which is the area with the greatest muscle insertion, as represented by the region of the masseter muscle. The direction of the force applied was approximate to that of the masseter fibres.

\subsection{Mechanical test}

The mechanical test was performed in a universal testing machine, Instron 5565 (Illinois Tool Works Inc., Norwood, MA, US). The load and crosshead displacement data were recorded during the test, thus allowing the creation of a load versus displacement graph.

The mandibles were subjected to testing for rigidity in a non-destructive test. Three displacement cycles were applied at a rate of $0.07 \mathrm{~mm} / \mathrm{s}$ for loading and $0.14 \mathrm{~mm} / \mathrm{s}$ for unloading, with an interval of $120 \mathrm{~s}$ between each cycle. The first displacement was $0.25 \mathrm{~mm}$, the second was $0.5 \mathrm{~mm}$ and the third was $0.75 \mathrm{~mm}$. The waiting time for the mandible returns to the starting position was two minutes. The angular coefficient of the straight line, adjusted to the points corresponding to the load period of the last cycle, was adopted as a stiffness value in the curve load versus displacement. The formula $a=y / x$, where a stiffness, $y=$ load, and $x=$ displacement, was adopted (Fig. 2). To calculate the mandibular stiffness, the third cycle was adopted as a standard because it had better uniformity in the graphic layout, possibly due to a better accommodation of the jaw on the metal apparatus. Fig. 2 shows the method used to calculate the stiffness of the mandible, and the results are shown in Fig. 3. A trend line was adjusted to the loading aspect of the register.

For the calculation of the horizontal displacement, rings were added with a metallic antenna in the bearings and a ruler was affixed in the support. The tips of the antennas moved as the displacement of the bearings that were located fixed in the angles of the mandibles. A camera was positioned to record the horizontal movement of the mandibular angles during the test, thus recording the horizontal displacement in millimeters. 


\section{Calculating Stiffness}

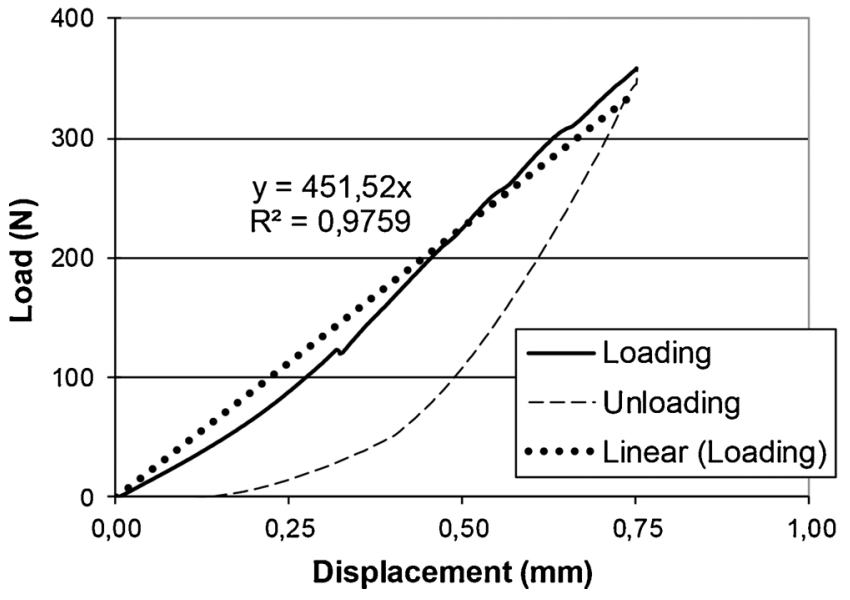

Fig. 2. Calculating the stiffness for the mandible in Fig. 3. $(a=451.52 \mathrm{~N} / \mathrm{mm})$.

\section{THREE DISPLACEMENT CYCLES}

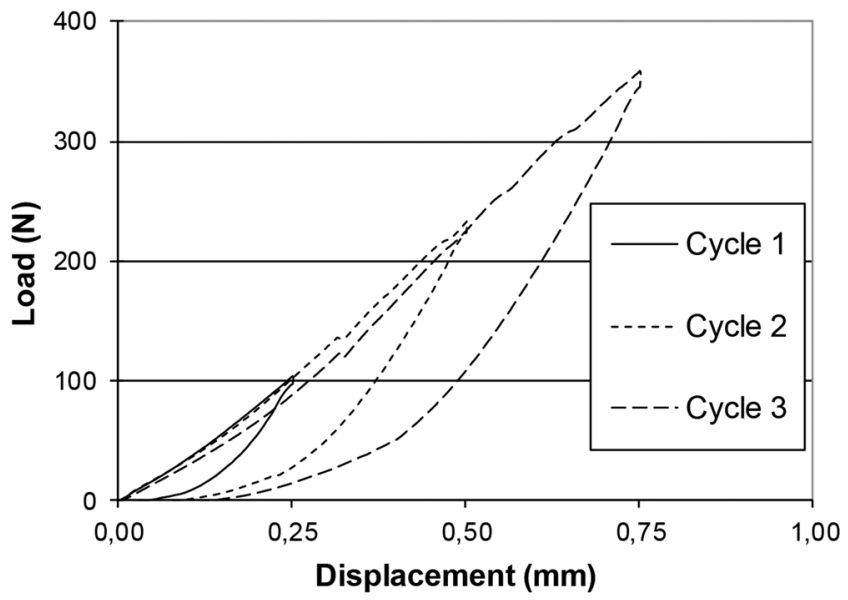

Fig. 3. One sample of the graphic record during the non-destructive test.

Mandibles typically fail initially due to fractures resulting from accidents. Once fixed and while the fracture consolidates, failure may occur before the occurrence of any fracture, which is why stiffness was used as an analytical parameter. Simple deformation or permanent displacement of the installed fixing can occur because it can change the maxilla-mandibular relationship achieved after fixation surgery. Accordingly, the most useful information would verify the load required to reach the elastic limit of the mandible or measure the maximum elastic displacement or maximum flexibility. Therefore, it would be necessary to load and unload (return to zero load) with sequentially increasing loads or displacements, until the existence of a permanent deformation can be verified. The elastic limit would be a load value between the last load value that did not cause permanent deformation and the first at which there was permanent displacement. Because these values require very lengthy trials and because permanent deformation in otherwise health mandibles does not occur even with $0.75 \mathrm{~mm}$ displacement, it seens that a more practical indicator would be to measure the resistance to elastic deformation of the fixation.

\section{Results}

The higid mandibles do not show permanent deformation after a displacement of $0.75 \mathrm{~mm}$. The obtained mean value of stiffness was $506 \pm 64 \mathrm{~N} / \mathrm{mm}$.

Fig. 3 presents an example of registration of the measurement of one of the mandibles. Notably, the stiffness remais the same in three cycles, and the mandible behaves visco-elastically during the discharge because it has a return line below the load line.

\section{Discussion}

This new apparatus allows movements to be performed in the three axes in space, which makes the studies of fixations for fractures or orthognathic surgery more reliable or complete. A previous study proposed a 3-point, bovine rib testing model to overcome the 2-point loading model. In this model, one end of the plated specimen is secured while the force is applied to the opposite end in a cantilevered beam model [3]. Thus, this would allow internal fixation systems on sagittal ramus osteotomies to be examined under conditions that more accurately represent the human mandible in function. However this model has limitations, such as its two-dimensional aspect, a force that was only applied vertically and plates that were not bent and only subjected to a single continuous load until failure [3]. The ideal would be to use human cadaver mandibles for these studies but this is rarely found in the literature [11]. There are issues such as availability, standardization of age, gender and presence of teeth as well as ethical aspects.

The mandible has the ability to flex inwards around the mandibular symphysis with changes in shape and decreases in mandibular arch width during opening and protrusion of the mandible. This movement, which ranges from a few micrometres to more than $1 \mathrm{~mm}$, occurs due to the contraction of lateral pterygoid muscles that pulls mandibular condyles medially and causes a sagittal movement of the posterior segments [12]. In addition, during biting and the power stroke of mastication, a combination of sagittal bending, corpus rotation, and transverse bending occurs. The result is a complex pattern of stresses and strains in the mandible - compressive, tensile, shear, and torsional [13].

A more appropriate study design should provide a special three point bending test that incorporates the major forces and freedom of movement to imitate the mandible in function, as demonstrated in this technical note. There is a support in the condylar region, with freedom for rotating and another support in the anterior region with freedom for displacement in an anterior direction. Finally, the load is applied to the mandibular angle region, which permits movement away from or nearing the angles. In this proposed model, the movements are closer to the mandibular mechanics function because, unlike previous designs, this support provides freedom of movement due to the three dimensional forces, which are generated by the applied load. Therefore, this new apparatus is a promising means for obtaining better evaluations of mandibular fixations.

\section{Conflicts of interest statement}

The authors declare that they have no conflict of interest.

\section{Role of the funding source}

No external funding, apart from the support of the authors' institution, was available for this study.

\section{Ethical approval}

All applicable international, national, and/or institutional guidelines for the care and use of animals were followed.

\section{Informed consent}

The manuscript does not contain clinical studies or patient data. 


\section{References}

[1] Asprino L, Consani S, de Moraes MA. Comparative biomechanical evaluation of mandibular condyle fracture plating techniques. J Oral Maxillofac Surg 2006;64:452-6. http://dx.doi.org/10.1016/j.joms.2005.11.017.

[2] Alkan A, Celebi N, Özden B, Bas B, Inal S. Biomechanical comparison of different plating techniques in repair of mandibular angle fractures. Oral Surg Oral Med Oral Pathol Oral Radiol Endod 2007;104:752-6. http://dx.doi.org/10.1016/j.tripleo. 2007.03.014.

[3] Armstrong JEA, Lapointe HJ, Hogg NJV, Kwok AD. Preliminary investigation of the bomechanics of internal fixation of sagital split osteotomies with miniplates using a newly designed in vitro testing model. J Oral Maxillofac Surg 2001;59:191-5. http://dx.doi.org/10.1053/joms.2001.20492.

[4] Uckan S, Schwimmer A, Kummer F, Greenberg AM. Effect of the angle of the screw on the stability of the mandibular sagital split ramus osteotomy: a study in sheep mandibles. Br J Oral Maxillofac Surg 2001;39:266-8. http://dx.doi.org/10.1054/ bjom.2000.0580.

[5] Özden B, Alkan A, Arici S, Erdem E. In vitro comparison of biomechanical characteristics of sagital split osteotomy fixation techniques. Int J Oral Maxillofac Surg 2006;35:837-41. http://dx.doi.org/10.1016/j.ijom.2006.03.001.

[6] Lima CJ, Falci SG, Rodrigues DC, Marchiori ÉC, Moreira RW. Mechanical and photoelastic analysis of conventional screws and cannulated screws for sagittal split osteotomy fixation: a comparative study. Oral Maxillofac Surg 2015;19:397-402. http://dx.doi.org/10.1007/s10006-015-0511-8.

[7] Law C, Bennani V, Lyons K, Swain M. Mandibular flexure and its significance on implant fixed prostheses: a review. J Prosthodont 2012;21:219-24. http://dx.doi. org/10.1111/j.1532-849X.2011.00798.x.

[8] Ribeiro-Junior PD, Magro-Filho O, Shastri KA, Papageorge MB. In vitro evaluation of conventional and locking miniplate/screw systems for the treatment of mandibular angle fractures. Int J Oral Maxillofac Surg 2010;39:1109-14. http://dx.doi. org/10.1016/j.ijom.2010.06.019.

[9] Pektas ZO, Bayram B, Balcik C, Develi T, Uckan S. Effects of different mandibular fracture patterns on the stability of miniplate screw fixation in angle mandibular fractures. Int J Oral Maxillofac Surg 2012;41:339-43. http://dx.doi.org/10.1016/j. ijom.2011.11.008.

[10] Trivellato PF, Pepato AO, Ribeiro MC, Sverzut CE, Trivellato AE. In vitro evaluation of the resistance of a $2.0-\mathrm{mm}$ titanium fixation system in the sectioned angle without continuity of the inferior border of the mandible. Int J Oral Maxillofac Surg 2014;43:559-63. http://dx.doi.org/10.1016/j.ijom.2013.10.002.

[11] Gutwald R, Alpert B, Schmelzeisen R. Principle and stability of locking plates. Keio J Med 2003;52:21-4. PMID: 12713018 .

[12] Sivaraman K, Chopra A, Venkatesh SB. Clinical importance of median mandibular flexure in oral rehabilitation: a review. J Oral Rehabil 2016;43:215-25. http://dx doi.org/10.1111/joor.12361.

[13] Van Eijden TMGJ. Biomechanics of the mandible. Crit Rev Oral Biol Med 2000;1:123-36. PMID: 10682903. 